\title{
Novel application of lithium and its isotopes in marine ecotoxicology
}

\author{
FANNY THIBON $^{1}$, LUCAS WEPPE $^{1,2}$, PACO \\ BuSTAMANTE $^{2,3}$, FRANCOIS OBERHÄNSLI ${ }^{4}$, MARC \\ METIAN $^{4}$, CARINE CHURLAUD ${ }^{2}$, MARYLINE MONTANES ${ }^{1}$, \\ ThOMAS LACOUE-LABARTHE ${ }^{2}$, YVES CHEREL ${ }^{5}$, AND \\ NATHALIE VIGIER ${ }^{1}$ \\ ${ }^{1}$ LOV- CNRS, Sorbonne Université - Villefranche-sur-Mer, \\ France. fanny.thibon@obs-vlfr.fr \\ ${ }^{2}$ LIENSs - CNRS, La Rochelle Université - La Rochelle, \\ France \\ ${ }^{3}$ IUF - France \\ ${ }^{4}$ IAEA - Principality of Monaco, Monaco \\ ${ }^{5}$ CEBC - CNRS, La Rochelle Université - Villiers-en-Bois, \\ France
}

Lithium (Li) and its isotopes are poorly documented in aquatic ecosystems, despite its massive and increasing industrial production, essentially for batteries, ceramics and medicine [1-2], and its potential in paleoceanography [3]. Here, we present field measurements and laboratory experiments that evidence $\mathrm{Li}$ accumulation and isotope fractionation in marine organisms. Li concentrations were analyzed in 433 organs or whole organisms (soft parts) of bivalves, cephalopods, crustaceans and fish from 3 oceans. Li concentrations and isotope ratios were also followed in soft tissues of mussels exposed in laboratory conditions for 5 days to different dissolved $\mathrm{Li}$ concentrations. Field results show that tissue $\mathrm{Li}$ in marine organisms range from 0.005 to 1.203 $\mu \mathrm{g} / \mathrm{g}$, with an average of $0.15( \pm 0.17) \mu \mathrm{g} / \mathrm{g}$. Results also evidence a systematic biodilution of $\mathrm{Li}$ along trophic chains, from bivalves (Li-rich) to carnivorous fish (showing the lowest Li levels). Among organs, significant differences are observed too. Higher Li concentrations are measured in gills and kidneys, suggesting a key role of the $\mathrm{Na}-\mathrm{H}$ Exchangers activity on Li transport. Experimentally, cultured mussel soft parts display $\delta^{7} \mathrm{Li}$ values systematically higher than seawater, contrasting to most fossil and modern shells measured thus far [4]. Li isotope fractionations between mussel and solution increase with the aqueous $\mathrm{Li}$ contents, and are modeled by increasing $\mathrm{Li}$ excretion $v s$. uptake rate ratio. Our model also shows that $\mathrm{Li}$ transport favors the light ${ }^{6} \mathrm{Li}$ isotope. Overall, these results show that $\mathrm{Li}$ and $\mathrm{Li}$ isotopes are promising in ecotoxicology and will help to better apprehend the impact of biological activity on fossile signatures.

[1] Choi et al. (1998) Nat. Commun. 10, 5371-5378 [2] Léguérinel et al. (2018) COMES seminar [3] Misra and Froelich (2012) Science. 335, 818-823 [4] Dellinger et al. (2018) Geochim. Cosmochim. Acta. 236, 315-335. 